\title{
Monitoring European wildcat Felis silvestris populations using scat surveys in central Spain: are population trends related to wild rabbit dynamics or to landscape features?
}

\author{
Jorge Lozano*, Emilio Virgós and Sara Cabezas-Díaz
}

\begin{abstract}
Background: Accurate data on the European wildcat Felis silvestris population trends are scarce for most of its range, despite this information being essential in assessing the threat status of the species. Moreover, ecological correlates of these population trends have never been evaluated. The aim of this study was to describe population trends of the European wildcat in a central region of Spain during the period 1997 to 2005 on both regional and local scales. Putative associations with several landscape features and wild rabbit population trajectories were also examined. Analyses were based on temporal variations of abundance indexes calculated for both species, which were derived from the respective frequencies of occurrence of scats along linear transects. Moreover, we propose monitoring wildcat populations across their range using scat surveys.
\end{abstract}

Results: Results showed that wildcat populations remained stable between the two survey periods considered, and variations in wildcat abundances were not associated with either habitat features or changes in rabbit abundances. Moreover, results suggested that wildcat predation does not limit the growth capacity of rabbit populations.

Conclusions: We propose standardized scat surveys as the most efficient methodology for monitoring wildcat populations across European regions. Problems with genetic analyses for correctly identifying carnivore scats are noted, which indicate that the best complementary method for monitoring wildcats is probably camera trapping (especially where hybridization is suspected). Furthermore, results showed that controlling wildcats to protect the rabbit populations is not justified.

Keywords: Habitat; Prey limitation; Population change; Scat; Sign surveys

\section{Background}

The European wildcat (Felis silvestris Schreber, 1775) is a medium-sized carnivore, the weight of which ranges from 2 to $7 \mathrm{~kg}$, with males averaging around $6 \mathrm{~kg}$ and females averaging $3 \mathrm{~kg}$ (Sunquist and Sunquist 2002). Wildcat distributions show a fragmented pattern, with populations across the entire Iberian Peninsula, northeastern France bordering Belgium, Germany, Scotland, Italy, Greece, Eastern Europe, Turkey, and the Caucasus (Stahl and Artois 1991; Nowell and Jackson 1996; Mitchell-Jones

\footnotetext{
* Correspondence: j.lozano.men@gmail.com

Área de Biodiversidad y Conservación, Departamento de Biología y Geología, ESCET, Rey Juan Carlos Universidad, C/ Tulipán s/n, Móstoles E-28933, Madrid,
} Spain predator (Malo et al. 2004), capable of surviving on a wide variety of prey (from insects to hares), but facultatively specializing on wild rabbit (Orcytolagus cuniculus L.) or rodents depending upon their availability (Malo et al.

The European wildcat is included in Annex IV of the European Habitats Directive (92/43/CEE), where 'strictly protected' species are listed, and in Annex II of the Bern Convention. Furthermore, the International Union for the Conservation of Nature (IUCN) considers that wildcat populations are declining throughout its range (for details, see Driscoll and Nowell 2010). Thus, for the European wildcat, being a legally protected species and 2004; Lozano et al. 2006; Piñeiro and Barja 2011). 
of conservation concern imply that further studies on its biology are crucial (Stahl and Artois 1991; Council of Europe 1993; Lozano and Malo 2012) to guarantee improved diagnoses of conservation problems and identify potential tools for preserving wildcats in Europe (Stahl and Artois 1991; McOrist and Kitchener 1994; Lozano et al. 2007). Indeed, in recent years, a significant increase in the number of studies on wildcats has taken place, especially in genetics (e.g., Pierpaoli et al. 2003; Lecis et al. 2006; Oliveira et al. 2008; Hertwig et al. 2009; Say et al. 2012), morphology (e.g., Yamaguchi et al. 2004; Kitchener et al. 2005; Krüger et al. 2009), trophic ecology (e.g., Malo et al. 2004; Biró et al. 2005; Lozano et al. 2006; Piñeiro and Barja 2011), and habitat preferences (e.g., Lozano et al. 2003, 2007; Biró et al. 2004; Klar et al. 2008; Monterroso et al. 2009; Lozano 2010).

However, our knowledge of many topics, such as the detailed distribution of wildcats in large European regions, their reproductive biology, and population dynamics, remains scarce (Stahl and Artois 1991; Stahl and Léger 1992; Sunquist and Sunquist 2002; Lozano and Malo 2012). In particular, up-to-date wildcat population trends and their ecological correlates have not been studied (Stahl and Artois 1991; Council of Europe 1993; Lozano and Malo 2012). Monitoring population trends of the species is a key tool for outlining conservation guidelines (see Council of Europe 1993) and, more importantly, to assign a threat status according to direct quantitative criteria (such as those used, for example, by the IUCN; see IUCN 2001). In the case of the European wildcat, the current assignments of threat status in most countries are not based on direct measurements of trends obtained from population monitoring. For example, this is the case of Spain, where the wildcat has been registered as 'near threatened' in the Red Data List of Mammals (Palomo et al. 2007). Although indirect criteria can be applied (e.g., IUCN 2001), higher quality assessments can be achieved with better confidence values when precise and direct data on population trends are available (see Lozano and Malo 2012).

Thus, standardized and rigorous population monitoring programs need to be established to improve our knowledge of the wildcat threat status in Spain and other European regions, using both accurate and objective information such as direct measures of density or abundance. In this sense, the use of scat surveys to derive appropriate abundance indexes (AIs) has proven effective in studies on distribution, habitat selection, and relationships between species (Lozano et al. 2003, 2007; Virgós et al. 2003; Barja and Bárcena 2005; Barea-Azcón et al. 2007; Simón et al. 2009; Lozano 2010; Piñeiro 2012). Consequently, these AIs obtained by monitoring programs over time allow the direct application of IUCN criterion A.2.b to assess the conservation status of a species for any region in its range (IUCN 2001). Moreover, these types of data can be also used to evaluate ecological correlates of population trends and build more robust demographic models (e.g., Barker and Sauer 1992; Thomas and Martin 1996; Fewster et al. 2000).

In addition, the study of wildcat population trends can be used as an initial step to studying predator-prey relationships (e.g., Hanski et al. 1991; Stenseth et al. 1997; Turchin 2003). Indeed, the study of predator and prey population trajectories over time can help elucidate potential limitation effects of predators on the growth capacity of prey populations. Furthermore, such work should indicate how more detailed studies on impacts of predators might be designed (see reviews about applied issues in Reynolds and Tapper 1996; Valkama et al. 2005).

The aims of this study were (1) to propose (on the basis of previously published studies) a standardized monitoring program methodology for wildcats by performing scat surveys and discuss its advantages versus other possible alternatives (especially genetic analyses), and as a result of these monitoring programs, IUCN criterion A.2.b could be directly applied to assess the species; (2) to evaluate the European wildcat population trend in an area of central Spain on a regional scale during the period 1997 to 2005; (3) to analyze ecological correlates of wildcat population trends at each location (local scale), which also includes the effects of variations in the population of its preferred prey, the wild rabbit; and (4) to explore potential limiting effects of wildcats on rabbits, based on the respective population trajectories.

\section{Methods}

\section{Study area and sampling design}

Analyses of population trends for both species were based on 39 survey locations scattered across Madrid and Toledo Provinces, central Spain (Figure 1), for which previous abundance data for both wildcats and rabbits at the same time (and for the same transects) are available (i.e., data corresponding to period 1, see below). Even though a number of studies dealing with diet and ecological requirements of wildcats were carried out in the region (see Lozano et al. 2003; Malo et al. 2004; Virgós and Travaini 2005; Lozano 2010), wildcat distribution continues to be poorly known and population trends are completely unknown.

The 39 plots were sampled twice, clustering the surveys into two periods of time (Table 1 ). Thus, period 1 contained surveys conducted in 1997 to 2002, and period 2 contained those carried out in 2004 and 2005. In period 1, we sampled 18 survey locations in autumn in northern and western Madrid Provinces. At these locations, the landscape is composed of typical Mediterranean vegetation formations (see Rivas-Martínez 1982). We also sampled 21 additional survey locations in spring 2002 in southeastern Madrid Province and in northern Toledo 


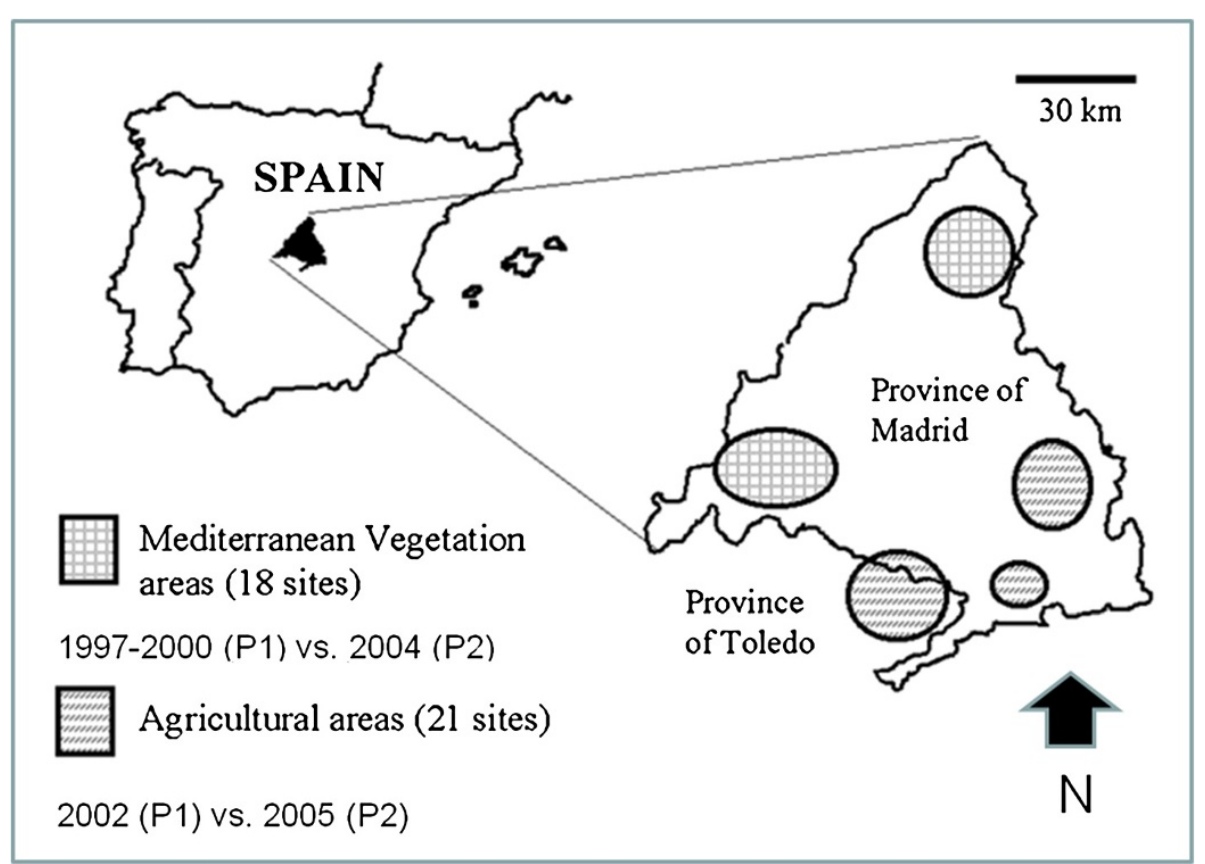

Figure 1 Study area. Survey locations in central Spain are shown according to the habitat type, which were distributed within Madrid and Toledo Provinces. Sampling dates for habitat types in relation to each compared period are shown.

Province. At these locations, the landscape consisted of agricultural areas and semiarid natural vegetation (RivasMartínez 1982). Surveys were conducted in autumn and spring because these seasons show similar climatic conditions in central Spain, making scat detection probabilities similar as well (Lozano et al. 2003; Lozano 2010). To evaluate population trends, the same survey locations were sampled again (i.e., in period 2) in 2004 (for the 18 survey locations of 1997 to 2000, which implied a time span of 4 to 7 years in relation to 2004) and 2005 (for the 21 survey locations of 2002, with a time span of 3 years with respect to 2005; Table 1). A minimum time span of 3 years is considered sufficient to detect changes in populations of both wildcats (Sobrino et al. 2009) and rabbits (Virgós et al. 2007). For both periods, the sampling protocol (see below), the season when sampling was performed, and the highly experienced observers involved in the surveys were the same, thus allowing direct comparisons to be made.

Detailed descriptions of the methodology and sampling protocol can be found in both Lozano et al. (2003) and Virgós et al. (2003). Briefly, each of the 39 survey locations consisted of a 1-km transect (along a path) where we recorded both wildcat scats and rabbit latrines (39 $1-\mathrm{km}$ transects in total). Each $1-\mathrm{km}$ transect was sampled once per period of time, and transects in the repeated survey (period 2) were the same to allow for comparisons. At each survey location (i.e., a 1-km transect), we calculated an AI for wildcats based on the frequency of occurrence of scats. Scats are left by wildcats along trails as territorial marks, thus indicating the presence of resident individuals (Corbett 1979; Lozano et al. 2003; Barja and Bárcena 2005; Piñeiro and Barja 2012). In most cases, scats found on the same trail belonged to

Table 1 Summary of the applied sampling protocol: number of survey locations, dates, and type of vegetation (habitat)

\begin{tabular}{|c|c|c|c|c|c|c|}
\hline $\begin{array}{l}\text { Number } \\
\text { of } \\
\text { locations }\end{array}$ & $\begin{array}{l}\text { Period } 1 \\
\text { (P1) }\end{array}$ & $\begin{array}{c}\text { Period } 2 \\
\text { (P2) }\end{array}$ & $\begin{array}{c}\text { Time span } \\
\text { (years) }\end{array}$ & $\begin{array}{c}\text { Type of } \\
\text { vegetation }\end{array}$ & $\begin{array}{l}\text { P1 Wildcat Al } \\
\text { (mean } \pm \text { SE) }\end{array}$ & $\begin{array}{c}\text { P2 Wildcat Al } \\
(\text { mean } \pm S E)\end{array}$ \\
\hline 8 & 1997 & 2004 & 7 & Mediterranean & & \\
\hline 2 & 1998 & 2004 & 6 & Mediterranean & & \\
\hline 3 & 1999 & 2004 & 5 & Mediterranean & $0.19 \pm 0.05$ & $0.27 \pm 0.09$ \\
\hline 5 & 2000 & 2004 & 4 & Mediterranean & & \\
\hline 21 & 2002 & 2005 & 3 & Agricultural & $0.11 \pm 0.04$ & $0.2 \pm 0.05$ \\
\hline
\end{tabular}

Mean values of the wildcat abundance index (Al) according to type of vegetation for both periods are shown. 
different individuals (Piñeiro 2012; Piñeiro et al. 2012), which precluded multiple sampling of individuals. We calculated the AI by dividing the number of 200-m segments where wildcat scat (or a small accumulation of scats likely belonging to the same individual) was found, by five (the total number of segments in each transect). For wild rabbits, we obtained the AI by recording the number of latrines found on transects $50 \mathrm{~m}$ long and $2 \mathrm{~m}$ wide conducted $200 \mathrm{~m}$ perpendicular to the principal transect on the trail (see also Virgós et al. 2003).

\section{Wildcat scat surveys}

The use of scats to carry out this type of ecological study dealing with carnivores has been questioned due to possible misidentification of the specific scat origin (e.g., Davison et al. 2002; Janecka et al. 2008; Harrington et al. 2010). Even so, a number of studies, also based on genetic analyses of scats, showed a high accuracy of the involved surveyors (Zuercher et al. 2003; Prugh and Ritland 2005; Barja et al. 2007; Harrington et al. 2008; Rosellini et al. 2008; Piñeiro 2012; Piñeiro et al. 2012). Furthermore, results from other studies indirectly showed the reliability and suitability of the methods based on feces when performed by experienced field researchers (e.g., Tuyttens et al. 2001; Sadlier et al. 2004; Webbon et al. 2004; Lozano et al. 2007). Scats of felids have physical characteristics that greatly differ from those of other carnivores, making them easy to be correctly identified by welltrained surveyors (e.g., Zuercher et al. 2003; Lozano and Urra 2007). In fact, when our criteria were used (e.g., Lozano et al. 2003, 2007; Lozano and Urra 2007), on the basis of genetic analyses, a success rate of $100 \%$ in identifying wildcat scat was demonstrated in an area of northwestern Spain where several species of carnivores were also present (see Piñeiro 2012; Piñeiro et al. 2012).

In addition, new evidence is becoming available which refutes the criticism that we do not know if for the carnivore species, the frequency of occurrence of signs (i.e., scats) reflects the population density. Indeed, such a direct relationship was demonstrated for the European badger Meles meles L. (Tuyttens et al. 2001) and the red fox Vulpes vulpes L. (Webbon et al. 2004). Note that finding these direct relationships cannot be expected if high rates of misidentification of the specific scat origin occur. Likewise, ongoing studies dealing with other carnivore species seem to indicate the same correlation between the scat frequency of occurrence and population density, thus allowing the use of these activity signs to test for changes in population density over time. In particular, genetic results on wildcat scats found along trails in northwestern Spain showed that most belonged to different individuals (Piñeiro 2012; Piñeiro et al. 2012). Therefore, it seems reasonable to expect that a significant variation in the wildcat $\mathrm{AI}$, based on the scat frequency of occurrence, will indicate a significant change in the number of individuals.

Concerning the presence of feral or domestic cats in the survey areas, their scats are not problematic if methods of Lozano et al. (2003) and Lozano and Urra (2007) are followed, as it was shown that in sympatric areas, only wildcats leave exposed scats along trails and on conspicuous sites such as tufts of grass (Schauenberg 1981; Barja and Bárcena 2005; Lozano and Urra 2007; Piñeiro and Barja 2012). Indeed, this was first reported by Corbett (1979) in Scotland, where a community of 68 domestic cats was studied, the scats of which were almost always buried but, in any case, never found in situations typically used by wildcats. Furthermore, it was shown that radio-collared cats avoided entering wildcat areas. In fact, feral cats (and also house pets) tend to avoid going into wildcat territories, where an agonistic encounter can occur (Corbett 1979). It is also expected that an intruder will try not to draw the attention of its wild counterparts, being careful not to leave traces of its visit. Moreover, it is very unlikely that a real feral cat population can survive in areas with the presence of wildcats due to competitive exclusion as domestic cats are weaker and therefore disadvantaged. Although some such feral cat populations can be found in Europe, they are surely exceptions that take advantage of particular circumstances, as for example, the case studied by Genovesi et al. (1995) in Italy. That feral cat population was found in a very peculiar area (a zone closed by wide irrigation channels), located in a region (the river Po Delta) where wildcats were not present, and depended on human pets to breed and remain in the area, as recognized by those authors.

The described pattern of defecation and marking behavior by wildcats and domestic cats in Scotland seems to be general: Lozano and Urra (2007) showed in central Spain that only 6 of 128 domestic cat scats were exposed (i.e., non-buried). Despite the existence of several paths and a number of feral cats living in the study area, no scat was found along trails or on conspicuous places. Moreover, it was very interesting to note that, in that case, wildcats were completely absent, but feral cats continued to avoid the use of trails to leave their scats. Finally, genetic results from recent studies seem to confirm the pattern: 37 scats found along trails in Ourense Province, northwestern Spain, belonged to wildcats, except for one cat scat with an uncertain identification (Piñeiro 2012; Piñeiro et al. 2012).

On the other hand and as an indirect approach, all of this evidence is consistent with results from wildcat distribution and habitat selection studies. For example, Lozano (2010) recently found only around $40 \%$ of trails (42 of 101) with the presence of cat scats in central Spain, a region with a very high density of domestic cats 
(corresponding to the highest density of human population in the country), which are widespread. If it were true that domestic cats leave exposed scats along trails as wildcats do, then to find almost $100 \%$ of trails with cat scats would have been expected. Furthermore, results for wildcat habitat selection obtained from that work matched those from studies applying non-scat-based methods elsewhere (e.g., compare Lozano 2010 with Monterroso et al. 2009).

In relation to hybrids, it should be taken into account that the hybridization level is low for most wildcat ranges (Pierpaoli et al. 2003; Oliveira et al. 2008; Hertwig et al. 2009; O’Brien et al. 2009; Lozano and Malo 2012), with hybrids overall being fairly scarce and the number of their scats irrelevant (excepting for some places at the regional scale; see Zuberogoitia et al. 2001; Pierpaoli et al. 2003; Lecis et al. 2006; Germain et al. 2008). Furthermore, wildcats and domestic cats belong to the same species (e.g., Sunquist and Sunquist 2002; Driscoll et al. 2007). In fact, hybrids play the same ecological role in the wild as wildcats, and many are even morphologically indistinguishable from them (e.g., Daniels et al. 2001; Biró et al. 2005; Hertwig et al. 2009; Krüger et al. 2009). Therefore, and especially in the latter case, it is not clear why an essential difference must be made between the two cat groups.

Indeed, in the Atlas of European Mammals, no difference between wildcats and hybrids is made (Mitchell-Jones et al. 1999), which is particularly remarkable for the case of Scotland, where the wildcat population is mostly formed by hybrids (e.g., Pierpaoli et al. 2003). In fact, it was suggested that the true Scottish wildcat may have disappeared (see French et al. 1988). However, the scientific literature dealing with wildcat distributions continues to state that the European wildcat is present in all Scottish territory (e.g., Sunquist and Sunquist 2002; Driscoll and Nowell 2010). Moreover, given that hybrids live in the wild, they continue to breed with wildcats and thus actively participate in wildcat population dynamics and influence demographic parameters (for more details, see French et al. 1988; Easterbee et al. 1991; Pierpaoli et al. 2003; Germain et al. 2008; Hertwig et al. 2009). Thus, in Scotland, this participation did allow the recovery of populations (Easterbee et al. 1991) and even of the original genotype to some extent (French et al. 1988). Therefore, due to theoretical and practical reasons (and consistent with current wildcat distribution maps), scats from hybrids should be considered as belonging to wildcats (for a similar suggestion, see Daniels and Corbett 2003; Kitchener et al. 2005).

\section{Other methodological issues}

Once the abundances were known for both periods of time, population trends (PTs) for each survey location were measured as the change in AIs and expressed as a percentage, used for the calculation the expression from Fewster et al. (2000), as follows:

$$
\mathrm{PT}=\left[\mathrm{AI}\left(\mathrm{t}_{2}\right)-\mathrm{AI}\left(\mathrm{t}_{1}\right)\right] /\left[\mathrm{AI}\left(\mathrm{t}_{1}\right) \times 100\right]
$$

where $t_{n}$ is each time period considered.

In addition to the AI for the species, we characterized the landscape composition of each survey location to study roles of possible ecological correlates in PTs. Thus, the following variables were calculated: forest cover (\%), pastureland cover (\%), cropland cover (\%), scrubland cover (\%), urban cover (\%), number of watercourses, and a roughness index. As in Lozano et al. (2003), to quantify landscape variables, land-use maps $(1: 50,000)$ were used to define a buffer of $9 \mathrm{~km}^{2}$ around each particular survey location (i.e., a $1-\mathrm{km}$ trail). In this area, landscape variables were measured through a grid with 121 evenly spaced points, where the number of points lying in each cover type was recorded. In addition, a roughness index was calculated as the mean number of $20-\mathrm{m}$ contour lines intercepted by four lines (one in each cardinal direction) that originate from the center of the $9-\mathrm{km}^{2}$ buffer. Finally, watercourses were recorded by counting the total number of streams - both permanent and seasonal - that crossed each buffer.

In summary, the main evidence-based assumptions of this study were as follows: (1) 3 years is sufficient to detect population changes for the considered species (Virgós et al. 2007; Sobrino et al. 2009); (2) well-trained, experienced surveyors are able to correctly identify wildcat scats (e.g., Lozano and Urra 2007; Piñeiro et al. 2012); (3) the AI based on the scat frequency of occurrence reflects the population density of the species (e.g., Lozano et al. 2003, 2007; Virgós et al. 2003; Simón et al. 2009; Piñeiro 2012); (4) scats found along trails and on conspicuous places in the field do not belong to domestic cats (Corbett 1979; Lozano and Urra 2007; Piñeiro et al. 2012); and (5) there are no essential differences between wildcats and their hybrids (especially from ecological and taxonomic points of view); therefore, they should be dealt as being the same entity (Mitchell-Jones et al. 1999; Daniels and Corbett 2003; Kitchener et al. 2005).

\section{Statistical analyses}

Normality and the homogeneity of the variance were verified for all variables, and those that did not account for parametric test requirements were normalized (Zar 1984) or tested for positive kurtosis (Underwood 1996). To examine changes in the species frequency of occurrence, $G$ tests were used.

Variables used to analyze the ecological correlates of wildcat PTs at the local scale were highly correlated with each other. To avoid spurious effects due 
to multicollinearity in the multiple regression analyses (see Graham 2003), we reduced landscape variables to a set of orthogonal and independent factors through a principal component analysis (PCA; Graham 2003; see Table 2). Then, the entire dataset was used to obtain a general linear model (GLM) with the PTs of wildcats as the response variable. PCA factors (which described the landscape from a quantitative point of view) were used with the habitat type (i.e., qualitatively considered: Mediterranean vegetation vs. agricultural/semiarid areas), and the PTs of rabbits as predictors. Furthermore, given that there was an important variation in the time span between sampling at different locations ( 4 to 7 years for the 18 survey locations in the Mediterranean vegetation areas and 3 years for the agricultural/semiarid locations, as indicated above), the number of months between samplings was also included as a covariate in the model to correct for this variation (see the 'months between samplings' variable in Table 3). All these analyses were performed using the software Statistica 6.0 (StatSoft 2001).

Finally, to evaluate PTs of both wildcats and rabbits at the regional scale, two GLMs for repeated measures were obtained to test for changes in values of AIs for the species between period 1 (i.e., AIs of the dataset constituted by samplings in 1997 to 2002) and period 2 (i.e., values of the dataset grouping samplings in 2004 to 2005). For wildcats, the GENMOD procedure using the GEE routines in SAS 9.2 (SAS Institute, Chicago, IL, USA) was performed, with different locations as the within-subject factor, a Poisson error, and log link. For rabbits, we used the MIXED procedure in SAS 9.2, with normal errors, an identity link, and location as the within-subject factor.

\section{Results and discussion Results}

At the regional scale, no variation between periods 1 and 2 in the number of survey locations with the presence of

\begin{tabular}{lcc}
$\begin{array}{l}\text { Table } 2 \text { Orthogonal factors obtained from a principal } \\
\text { component analysis using landscape variables at each } \\
\text { survey location }(\boldsymbol{n}=\mathbf{3 9})\end{array}$ & Factor $\mathbf{1}$ & Factor $\mathbf{2}$ \\
\hline Variable & $0.85^{\mathrm{a}}$ & 0.06 \\
\hline Pastureland cover & $-0.95^{\mathrm{a}}$ & -0.00 \\
Cropland cover & $0.86^{\mathrm{a}}$ & 0.02 \\
Scrubland cover & $0.72^{\mathrm{a}}$ & -0.21 \\
Forest cover & 0.01 & $0.99^{\mathrm{a}}$ \\
Urban cover & $0.89^{\mathrm{a}}$ & 0.06 \\
Roughness index & $0.82^{\mathrm{a}}$ & 0.01 \\
Number of watercourses & 4.366 & 1.028 \\
Eigenvalue & 62.37 & 14.69 \\
\hline Percentage of explained variance & $019 \mathrm{n}$
\end{tabular}

${ }^{a}$ Indicates a significant correlation $(p<0.05)$ of the original variables with the extracted factor. wildcats was detected. In both time periods, wildcats were found at 18 of the 39 locations sampled. However, some differences were observed in particular survey locations. Thus, in period 2, wildcats were detected at six new locations, whereas at another six different locations, the species was present during period 1 but was not detected in period 2 .

When we analyzed the pattern considering the habitat type, we detected wildcats at ten survey locations of Mediterranean vegetation in period 1 , but at only seven in period 2. In contrast, in the agricultural/semiarid habitat, wildcats increased from 8 detections in the first period to 11 in the second period. However, these differences were not significant $(G=3.91, d f=2, p=0.14)$.

At the local scale (survey locations), we detected increases in wildcat abundance at 15 of 39 sites and decreases at 6 sites. In the remaining 18 sites, wildcat abundances were stable. Interestingly, rabbit abundances increased at 16 of the total survey locations, including 6 sites where wildcats also increased. Furthermore, rabbits increased in seven survey areas where wildcats remained stable. Finally, in only 3 of 39 survey locations was there a reduction in wildcat abundances observed alongside an increase in rabbits. However, none of these changes was associated ( $\mathrm{G}=2.43, d f=4, p=0.66)$.

The PCA with landscape variables produced two principal components (PCA factors), which explained $77 \%$ of the total variance (Table 2). The first factor roughly separated areas with a large number of watercourses and high proportions of pasture, scrubland, and forests (positive scores) from plain agricultural areas (negative scores). The second factor described a gradient from urbanized landscapes (positive scores) to more natural areas (negative scores).

The analysis performed with PTs of wildcats as a response variable rendered no significant model (GLM: $F_{5,33}=0.26, p=0.932$ ). Indeed, no correlation among variables was found (Table 3 ). In these cases, the observed variation in wildcat abundances between periods was not associated with any landscape feature nor with changes in rabbit AIs at survey locations; thus, there was no significant relationship between wildcat and rabbit PTs $(r=-0.05, p=0.75$; Figure 2, Table 3).

On the other hand, in relation to wildcat AI values at the regional scale, a significant difference between periods 1 and 2 was not detected (chi square $=2.33, d f=1, p=0.13$; Figure $3 \mathrm{~A}$ ), thus indicating that the wildcat population remained stable in the region. In strong contrast, the rabbit population significantly increased between the two periods $\left(F_{1,38}=6.8, p=0.013\right.$; see Figure $\left.3 \mathrm{~B}\right)$. Therefore, population trends of the two species were completely independent.

\section{Discussion}

This study describes results of population trends of wildcats in central Spain, employing an objective and 


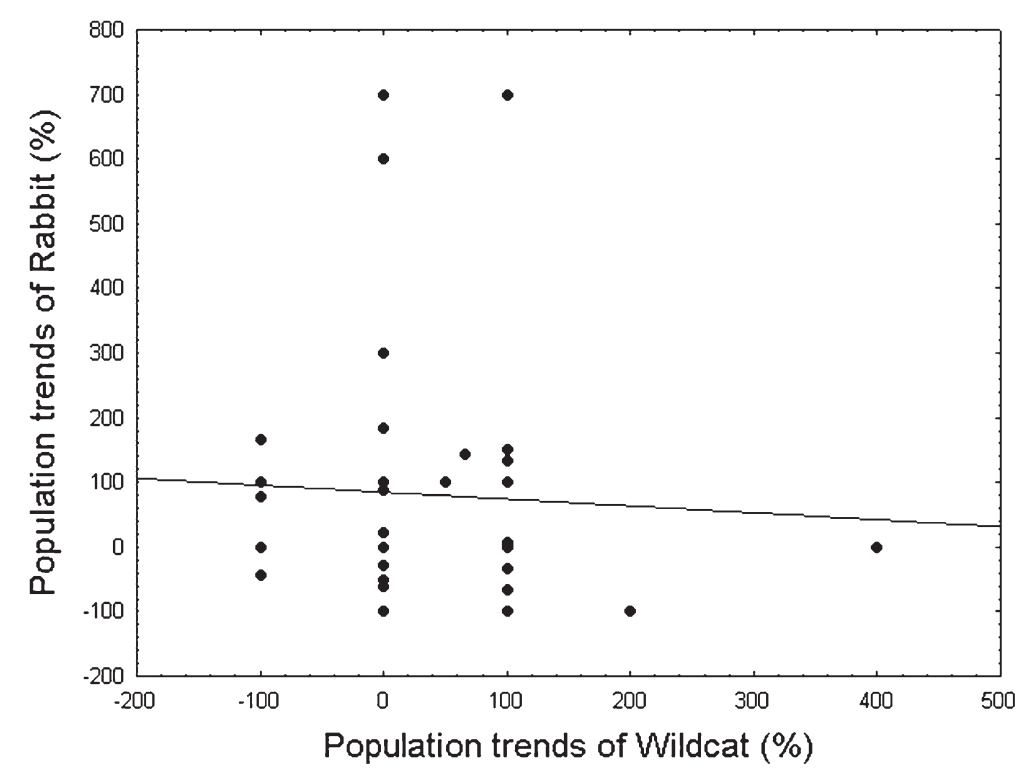

Figure 2 Wildcat-rabbit relationship. No significant correlation was found between wildcat and rabbit population trends (PTs) in the study area for the considered periods $(r=-0.05, p=0.75)$.

standardized methodology, simultaneously considering putative ecological correlates and the abundance variation of one of its main prey species (the wild rabbit in this case; see Lozano et al. 2006). Despite its limited scope, this is also an empirical approach to study the wildcat predator-prey relationship using population trajectories.

\section{Scat surveys for monitoring wildcat populations}

The monitoring methodology was based on scat surveys, which are indicative of several ecological issues for both wildcats and rabbits (Lozano et al. 2003, 2007; Virgós et al. 2003; Barea-Azcón et al. 2004; Malo et al. 2004; Barja and Bárcena 2005; Simón et al. 2009; Lozano 2010;

Table 3 Pearson correlations of all variables examined in this study with PTs of wildcats $(n=39)$

\begin{tabular}{lc}
\hline Variable & Wildcat PTs \\
\hline Months between samplings & 0.03 \\
Pastureland cover & 0.15 \\
Cropland cover & 0 \\
Scrubland cover & -0.22 \\
Forest cover & -0.04 \\
Urban cover & -0.16 \\
Roughness index & -0.15 \\
Number of watercourses & -0.12 \\
PCA factor 1 & -0.07 \\
PCA factor 2 & -0.16 \\
Rabbit population trends & -0.05 \\
\hline
\end{tabular}

No correlation was significant. PCA, principal component analysis.
Piñeiro 2012). Thus, according to IUCN quantitative criterion A.2.b, it would be possible to qualify the species as critically endangered, endangered, vulnerable, or near threatened depending on observed reductions of $80 \%$, $50 \%, 30 \%$, or $20 \%$, respectively, in the proposed AI within a period of 10 years or three generations (IUCN 2001).

Only in those areas of Europe with the presence of the other wild felid species, Iberian lynx (Lynx pardinus, Temminck 1827) or European lynx (Lynx lynx, Schreber 1777), could confusion with wildcat scats be possible and genetic analysis of scats would be necessary (Guzmán et al. 2004; Alda et al. 2008; Harrington et al. 2010). Even so, the technical staff and scientists working on recovery programs of Iberian lynx in Spain are convinced that most scats can be differentiated without genetic analyses when field experience is extensive enough (as the size, shape, and color of lynx scats considerably differ; Gil-Sánchez (personal communication)). Perhaps the same could be said about European lynx scats (at least, it is expected that their physical measurements, such as the diameter, would be significantly larger than those of wildcat scats). However, in those particular cases in which researchers suspect that scat surveys may not be completely reliable due to any reason (including the lack of sufficient field experience), the data obtained must be verified using complementary methods such as genetic analysis or camera trapping, which cannot be the first option for monitoring wildcat populations across Europe due to their higher economic costs (e.g., Barea-Azcón et al. 2007; Harrington et al. 2010). Even so, there are many large areas of Europe where the wildcat is the only wild felid species present (Mitchell-Jones et al. 1999) so that monitoring based on 

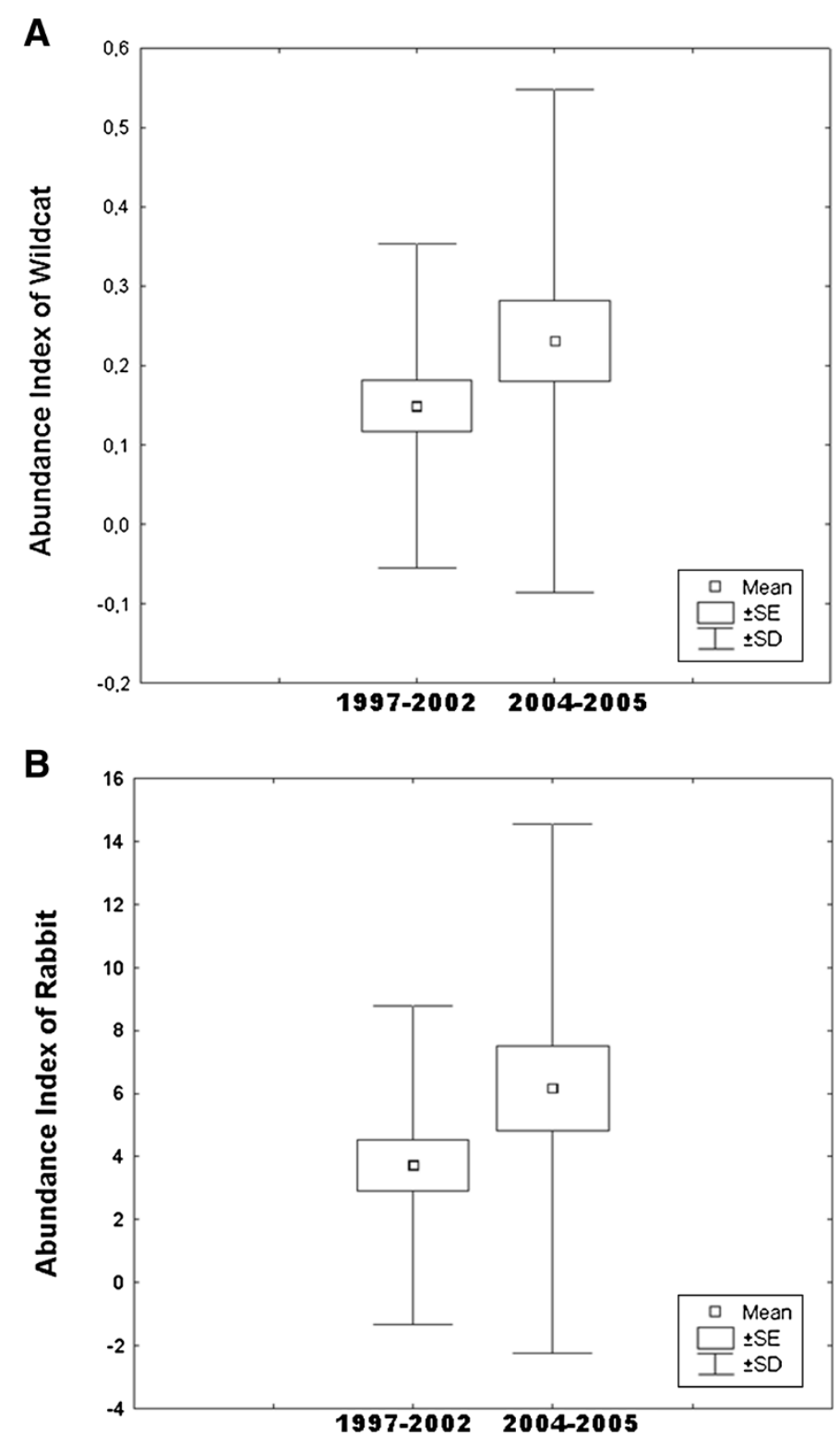

Figure 3 Species trends. Mean Als for period 1 (1997 to 2002) and period 2 (2004 to 2005) of (A) the wildcat and (B) rabbit at a regional scale. The difference in rabbit abundances was statistically significant.

scat surveys can be applied without identification problems in a wide extent of the wildcat's range.

Indeed, as demonstrated by comparison to other methods for monitoring animal populations, scat surveys show a number of important advantages, especially when studying carnivore species at large spatial scales, including both logistic and economic factors (for details, see Lozano et al. 2003; Sadlier et al. 2004; Barea-Azcón et al. 2007; McCarthy et al. 2008). In terms of the European wildcat, we urgently need easy and relatively cheap methods for monitoring populations of this threatened species across all of its wide range. It does not seem realistic to propose a large-scale population monitoring on the basis of more expensive or even prohibitive (as recognized by Harrington et al. 2010) alternative methods such as genetic analyses or camera trapping. Nevertheless, genetic analyses are needed when facing other types of questions: for example, both the identification of hybrids and the monitoring of their frequency of occurrence within populations over time continue to be relevant for the conservation of the European wildcat genotype (e.g., French et al. 1988; Driscoll and Nowell 
2010). Moreover, camera trapping can be a good complementary non-genetic-based method (see below) to monitor wildcats where hybridization is suspected, given that pictures can be used to discriminate hybrids (see Sarmento et al. 2009; Can et al. 2011; Kilshaw and Macdonald 2011; Anile et al. 2012).

Certainly, it was shown that well-trained surveyors can correctly identify wildcat scats when proper identification criteria are applied (Piñeiro 2012; Piñeiro et al. 2012). In this sense, the field experience of observers involved in surveys should be as wide as possible: surveyors not only need to know the correct diagnostic criteria of scats belonging to the target carnivore but also those of sympatric species, the marking behavior, and the potential variation of scats depending on the region, habitat, season, etc. Therefore, to become a good surveyor, much time is needed for training (although less time must be spent, around 1 year, if the surveyor specializes only in a particular region). It is surely true that identification of scats from very similar species is difficult or even impossible (e.g., Barja et al. 2007; Harrington et al. 2010). Even so, the simplest and most parsimonious explanation for contradictory results about scat identification obtained in studies dealing with mustelids in Europe, for instance, compare Davison et al. (2002) with Rosellini et al. (2008) in relation to identifying European pine marten scats or works by Harrington et al. $(2008,2010)$ on mink scat identification in different parts of the UK, is that observers misidentifying scats really did not have enough experience to carry out the surveys in some particular study areas (where more training was probably needed).

Furthermore, other more complex possibilities for scat misidentification were also intuited by Davison et al. (2002): red foxes may genetically contaminate scats from other species by urinating on them, which is a typical behavior of canids. Thus, the very high rates of putative confusion with 'red fox scat' shown by some studies based on genetic analyses (e.g., Davison et al. 2002; Janecka et al. 2008; Harrington et al. 2010; Monterroso et al. 2013) caused us to suspect that Davison's hypothesis may be correct. In particular, Monterroso et al. (2013) found an error rate in species assignment of scats based on morphology as high as $88 \%$ for wildcats, which was usually confused with putative red fox scats. Those authors suggested that scat identification accuracy rates are circumstance-specific and that scat-based studies should implement measures allowing researchers to determine their own circumstance-specific error rates. However, a misidentification of $88 \%$ seems too high for experienced researchers. The most probable hypothesis is that red fox urine contamination misdirected their conclusions. In fact, no study based on genetic analyses for identifying carnivore scats has correctly addressed this problem, and if this confounding factor is not controlled within the analytical process, results obtained from genetic analyses will not be totally reliable (see also other problems associated with genetic analyses in Schwartz and Monfort 2008). Nevertheless, although genetic techniques can improve and successes are recognized (e.g., Waits and Paetkau 2005; Schwartz and Monfort 2008; Luikart et al. 2010; Lin et al. 2011; Wu et al. 2012), the high cost of these types of methods will continue to be an important problem when they are applied on a massive scale considering the wide European wildcat range.

Therefore, we advocate the establishment of monitoring programs based on scat surveys of wildcat populations across different European regions carried out by well-trained observers as the most efficient standardized methodology (e.g., Barea-Azcón et al. 2007) and the most feasible method for application on large spatial scales (and to be periodically repeated over time). If needed, camera trapping seems to be the best complementary method.

\section{Wildcat trends and the role of habitat}

Results indicated that wildcat populations remained stable in central Spain in 1997 to 2005, when the species was recorded in $46 \%$ of survey locations. A similar pattern was found in Granada Province (southeastern Spain) in the 1990s (Barea-Azcón et al. 2004) and in the Aragón region (northeastern Spain) between 1992 and 2006 (Sobrino et al. 2009), where wildcat populations also remained stable. Population trends can be directly assessed by changes in both AIs at the survey locations and their number with confirmed presence of the species. Thus, population densities can change while leaving the number of survey locations with wildcat presence unchanged. However, a significant variation in this number also indicates a change in the population trend. In this regard, survey locations (i.e., 1-km trails) with species presence used in this study can be equivalent (depending on factors such as their spatial distribution and the considered scale) to areas of occupancy used in other works (e.g., IUCN 2001; Heltai et al. 2006). In the case of central Spain, results show stability in the two parameters: the average AI did not change between periods, and the number of survey locations with wildcat presence was the same. Nevertheless, to evaluate the species population trend at a national scale, more studies in other Spanish regions are needed. Moreover, population monitoring should be continued over time (Barker and Sauer 1992; Fewster et al. 2000) given that species population trends may vary concomitantly with several circumstances (e.g., Turchin 2003; Virgós et al. 2007) or differently by region (e.g., Stenseth et al. 1999).

On the other hand, the reported stability seems to be a consequence of the dynamics of local populations in that we detected changes in both the presence of the wildcat 
over time and in AIs. Thus, we recorded 'apparent extinctions' at six survey locations and 'apparent colonizations' at another eight during the study. This dynamism was not observed at the regional scale because local variations were masked when all data were combined. However, determining the causes of these local variations in populations is not easy; for example, such variations were not associated with any landscape feature.

Overall, the habitat type and structure appear to be of minor relevance to explain the distribution and abundance of the European wildcat (Lozano et al. 2003; Lozano 2010), which were better explained by food availability (Easterbee et al. 1991; Urra 2003; Lozano et al. 2007). From this perspective, the presence of wildcats in agricultural and semiarid areas is not surprising (see Lozano 2010) because such areas maintain an important availability of rodents and rabbits, staple prey items of this species (Lozano et al. 2006). Thus, observed variations in the presence and abundance of wildcats may be dependent on changes in the availability of nonmeasured trophic resources (but see the case of wild rabbits below). Furthermore, predator control programs on hunting lands was reported to be a clear factor related to the decreasing abundance of wildcats (Virgós and Travaini 2005). Thus, it is possible that differential pressure by predator control intensity over time could also explain part of the wildcat variation.

\section{Wildcat-rabbit relationship}

A comparison of wildcat and rabbit population trends indicated that they were not associated, at neither the regional nor local scales. Even though the wildcat population in the region remained stable, the number of rabbits significantly increased, and at survey locations, variations in the AIs for both species were completely independent. In this scenario, the pattern discovered can be considered preliminary evidence for a lack of limitation of rabbit populations due to wildcat predation, at least for the scales and range of rabbit densities examined.

Limitation in this context is usually defined as an impediment to prey population growth (e.g., Boutin 1995; Korpimäki and Krebs 1996; Sinclair and Pech 1996; Moorhouse et al. 2003). Given that increases in rabbits were not due to reductions in wildcats and that the rabbit population doubled in mean abundance during the study period, it is thus obvious that rabbit population growth was not limited by wildcats. This result is important because it comes from a Spanish region where the hunting community advocates predator control programs, arguing that predators such as wildcats are systematically limiting populations of game species, an argument refuted by the findings shown here for rabbits.

It could be supposed that a putative decrease in the abundances of other predators that feed mainly on rabbits could mask a link between wildcat and rabbit populations, allowing rabbits to increase in number despite wildcat numbers remaining stable. Nonetheless, such a possibility is very unlikely after examining available data on predator trends in the studied region. Indeed, during the study period, most raptor species (such as hawks, eagles, and owls, which in general are not the aim of predator control programs) showed stable populations or even an increase in the number of pairs (Martí and Del Moral 2003; Madroño et al. 2004; Del Moral 2009). In relation to carnivorous mammals that prey on rabbits, the most important species present in the area is the red fox. Although data for the same wildcat survey locations of this work were not available, existing information from nearby areas and at a regional scale does not indicate a decrease in fox abundances (JL, EV, SC-D unpublished data). This is probably due to red foxes usually not suffering from implementation of predator control campaigns in a significant way (Virgós and Travaini 2005; Lozano et al. 2013).

On the other hand, it is perhaps not surprising to find no link between wildcat and rabbit population dynamics. Such a lack of a link was also found between red fox and rabbit populations in the Aragón region (northeastern Spain), where again the predator did not limit the growth capacity of lagomorphs (Williams et al. 2007). Furthermore, it seems that, in general, the predation impact on rabbit populations in Spain is very low (see the cases of red fox, Iberian lynx, and Bonelli's Eagle Aquila fasciata in Calzada 2000 and Moleón et al. 2011). Therefore, a relationship of predators with rabbit population dynamics and specifically limitations on increases in rabbit numbers was not expected.

Based on this lack of a limitation, we speculated that wildcats only take a doomed surplus of the rabbit population, thus acting as a compensatory force of mortality rather than an additive one (see Errington 1946; Banks 1999). In fact, the compensatory or additive nature of predation is a key element that should be considered in game management and conservation conflicts (e.g., Reynolds and Tapper 1996; Valkama et al. 2005). Additive mortality occurs when individuals are removed from the population that otherwise would not have disappeared (an additional cause of mortality), which implies an alteration in the dynamics, and population growth may thus be limited (Boutin 1995; Korpimäki and Krebs 1996; Sinclair and Pech 1996; Schaub and Lebreton 2004). In contrast, compensatory mortality appears in the opposite case, when affecting a surplus of individuals that do not contribute to the population dynamics (i.e., that exert no type of limitation on population growth), as they are eliminated for one reason or another, thus compensating for this population surplus (i.e., the 'doomed surplus' concept of Errington 1946; see also Burnham and Anderson 1984; Banks 1999; Schaub and Lebreton 2004). Thus, predator 
control is based on the argument of additive (limiting) effects of predators on prey (game) species, which produces a reduction in hunting bags and economic revenues for game owners (Reynolds and Tapper 1996; Côté and Sutherland 1997; Virgós and Travaini 2005). However, in predatorprey systems where a doomed surplus is taken, predator control would be a useless practice. Therefore, it is essential to carry out more studies to correctly identify the nature of predation in order to achieve well-informed game management, especially when threatened species, such as the European wildcat, are being heavily affected by currently applied measures (Virgós and Travaini 2005; Lozano et al. 2013).

On the other hand, considering the positive relationship previously described for abundances of wildcats and rabbits (see Lozano et al. 2003, 2007), an association between variations in the AIs of both species would be expected. However, the increase in rabbits did not trigger an increase in wildcats. Although the reasons are unknown to us, a number of factors could be considered to hypothetically explain these observations. For instance, it could be that the time needed to detect a numerical response from wildcats to rabbit density variations would be longer than the period the study considered. Nonetheless, it was shown that changes in wildcat populations can be detected in less than 3 years (Sobrino et al. 2009). Indeed, wildcats show an apparently moderately high reproductive capacity: almost four (range, 1 to 8 ) cubs per female and even the possibility in some cases of producing two litters per year if food sources are especially abundant (e.g., Nowell and Jackson 1996; Muñiz and Sanz 2010). Then, it is expected that the numerical response of wildcat populations would be sufficiently fast to detect significant changes in 3 years or even less. It could also be the case that legal or illegal predator control in the study area, which numerically affects wildcats, is disturbing the normal population dynamics of the species. In fact, where predator control occurs, wildcat presence can decrease by up to $50 \%$ (Virgós and Travaini 2005). Although wildcat populations may increase in some areas, predator control may prevent this growth at other locations and maintain a stable population at the regional scale. Furthermore, predator responses might not be linear, and thus, populations might not increase on a local scale despite an increase in rabbits due to the existence of limits in the habitat carrying capacity for wildcats and saturation effects (see Turchin 2003).

However, all these results should encourage new studies on wildcat population trends, ecological correlates, human factors (for example predator control programs), and wildcat-rabbit population dynamic relationships in the near future, which could also examine numerical and functional responses of wildcats over a range of densities of rabbits and other prey species across Europe.

\section{Conclusions}

We propose standardized scat surveys as the most efficient methodology for monitoring wildcat populations across European regions. Problems with genetic analyses for correctly identifying carnivore scats are noted, which indicate that the best complementary method for monitoring wildcats is probably camera trapping (especially where hybridization is suspected). Furthermore, results showed that controlling wildcats to protect rabbit populations is not justified.

\section{Competing interests}

The authors declare that they have no competing interests.

\section{Authors' contributions}

$J \mathrm{~L}, \mathrm{EV}$, and SC-D designed the study and carried out scat surveys in both periods of time; $J L$ and EV performed the statistical analyses and drafted the manuscript. All authors read and approved the final manuscript.

\section{Acknowledgements}

We thank all participants in the field surveys during the first period, especially JG Casanovas, DL Huertas, and AF Malo. The English version was kindly revised by $V$ Herranz and D Ward. Two anonymous referees provided comments which greatly improved the final version of the manuscript.

Received: 2 April 2013 Accepted: 2 July 2013

Published: 30 September 2013

\section{References}

Alda F, Inogés J, Alcaraz L, Oria J, Aranda A, Doadrio I (2008) Looking for the Iberian lynx in central Spain: a needle in a haystack? Anim Conserv 11:297-305

Anile S, Amico C, Ragni B (2012) Population density estimation of the European wildcat (Felis silvestris silvestris) in Sicily using camera trapping. Wild Biol Pract 8:1-12

Banks PB (1999) Predation by introduced foxes on native bush rats in Australia: do foxes take the doomed surplus? J Appl Ecol 36:1063-1071

Barea-Azcón JM, Ballesteros-Duperón E, Moleón M, Gil-Sánchez JM, Virgós E, Chirosa M (2004) Distribución de los mamíferos carnívoros en la provincia de Granada. Acta Granatense 3:43-53

Barea-Azcón JM, Virgós E, Ballesteros-Duperón E, Moleón M, Chirosa M (2007) Surveying carnivores at large spatial scales: a comparison of four broadapplied methods. Biodivers Conserv 16:1213-1230

Barja I, Bárcena F (2005) Distribución y abundancia del gato montés (Felis silvestris) en un área protegida de Galicia (NO España): factores de hábitat implicados y relación con la presencia de zorro y marta. Galemys 17:29-40

Barja I, Silván G, Rosellini S, Piñeiro A, González-Gil A, Camacho L, Illera JC (2007) Stress physiological responses to tourist pressure in a wild population of European pine marten. J Steroid Biochem Mol Biol 104:136-142

Barker RJ, Sauer JR (1992) Modeling population change from time series data. In: McCullogh DR, Barrett R (ed) Wildlife 2001: populations. Elsevier, New York, pp 182-194

Biró Z, Szemethy L, Heltai M (2004) Home range sizes of wildcats (Felis silvestris) and feral domestic cats (Felis silvestris f. catus) in a hilly region of Hungary. Mamm Biol 69:302-310

Biró Z, Lanszki J, Szemethy L, Heltai M, Randi E (2005) Feeding habits of feral domestic cats (Felis catus), wild cats (Felis silvestris) and their hybrids: trophic niche overlap among cat groups in Hungary. J Zool 266:187-196

Boutin S (1995) Testing predator-prey theory by studying fluctuating populations of small mammals. Wildl Res 22:89-100

Burnham KP, Anderson DR (1984) Tests of compensatory vs. additive hypotheses of mortality in mallards. Ecology 65:105-112

Calzada J (2000) Impacto de predación y selección de presa del lince ibérico y el zorro sobre el conejo. PhD thesis. University of León

Can ÖE, Kandemir I, Togan I (2011) The wildcat Felis silvestris in northern Turkey: assessment of status using camera trapping. Oryx 45:112-118 
Corbett LK (1979) Feeding ecology and social organization of wildcats (Felis silvestris) and domestic cats (Felis catus) in Scotland. PhD dissertation. University of Aberdeen, Aberdeen

Côté IM, Sutherland WJ (1997) The effectiveness of removing predators to protect bird populations. Conserv Biol 11:395-405

Council of Europe (1993) Seminar on the biology and conservation of the wildcat (Felis silvestris). Council of Europe, Strasbourg

Daniels MJ, Corbett L (2003) Redefining introgressed protected mammals: when is a wildcat a wild cat and a dingo a wild dog? Wildl Res 30:213-218

Daniels MJ, Beaumont MA, Johnson PJ, Balharry D, Macdonald DW, Barratt E (2001) Ecology and genetics of wild-living cats in the north-east of Scotland and the implications for the conservation of the wildcat. J Appl Ecol 38:146-161

Davison A, Birks JDS, Brookes RC, Braithwaite TC, Messenger JE (2002) On the origin of faeces: morphological versus molecular methods for surveying rare carnivores from their scats. J Zool 257:141-143

Del Moral JC (2009) El águila real en España. Población reproductora en 2008 y método de censo. SEO/BirdLife, Madrid, p 185

Driscoll C, Nowell K (2010) Felis silvestris. In: IUCN 2012. IUCN red list of threatened species. Vers. 2012.1. http://www.iucnredlist.org. Accessed 2 Aug 2012

Driscoll C, Menotti-Raymond M, Roca AL, Hupe K, Johnson WE, Geffen E, Harley E, Delibes M, Pontier D, Kitchener AC, Yamaguchi N, O'Brien SJ, Macdonald D (2007) The near eastern origin of cat domestication. Science 317:519-523

Easterbee N, Hepburn LV, Jefferies DJ (1991) Survey of the status and distribution of the wildcat in Scotland, 1983-1987. Nature Conservancy Council for Scotland, Edinburgh

Errington PL (1946) Predation and vertebrate populations. Q Rev Biol 21:144-177

Fewster RM, Buckland ST, Siriwardena GM, Baillie SR, Wilson JD (2000) Analysis of population trends for farmland birds using generalized additive models. Ecology 81:1970-1984

French DD, Corbett LK, Easterbee N (1988) Morphological discriminants of Scottish wildcats (Felis silvestris), domestic cats (F. catus) and their hybrids. J Zool 214:235-259

Genovesi P, Besa M, Toso S (1995) Ecology of a feral cat Felis catus population in an agricultural area of northern Italy. Wild Biol 1:233-237

Germain E, Benhamou S, Poulle ML (2008) Spatio-temporal sharing between the European wildcat, the domestic cat and their hybrids. J Zool 276:195-203

Graham MH (2003) Confronting multicollinearity in ecological multiple regression. Ecology 84:2809-2815

Guzmán JN, García FJ, Garrote G, de Ayala RP, Iglesias C (2004) El Lince ibérico (Lynx pardinus) en España y Portugal. Censo-diagnóstico de sus poblaciones. Dirección General para la Biodiversidad, Ministerio de Medio Ambiente, Madrid, p 184

Hanski I, Hansson L, Henttonen H (1991) Specialist predators, generalist predators, and the microtine rodent cycle. J Anim Ecol 60:353-367

Harrington LA, Harrington AL, Macdonald DW (2008) Estimating the relative abundance of American mink Mustela vison on lowland rivers: evaluation and comparison of two techniques. Eur J Wildl Res 54:79-87

Harrington LA, Harrington AL, Hughes J, Stirling D, Macdonald DW (2010) The accuracy of scat identification in distribution surveys: American mink, Neovison vison, in the northern highlands of Scotland. Eur J Wildl Res 56:377-384

Heltai M, Biró Z, Szemethy L (2006) The changes of distribution and population density of wildcats Felis silvestris Schreber, 1775 in Hungary between 1987-2001. Nat Conserv 62:37-42

Hertwig ST, Schweizer M, Stepanow S, Jungnickel A, Böhle U-R, Fischer MS (2009) Regionally high rates of hybridization and introgression in German wildcat populations (Felis silvestris, Carnivora, Felidae). J Zool Syst Evol Res 47:283-297

IUCN (2001) IUCN red list categories and criteria: version 3.1. IUCN Species Survival Commission, Gland

Janecka JE, Jackson R, Yuquang Z, Diqiang L, Munkhtsog B, Buckley-Beason V, Murphy WJ (2008) Population monitoring of snow leopards using noninvasive collection of scat samples: a pilot study. Anim Conserv 11:401-411

Kilshaw K, Macdonald DW (2011) The use of camera trapping as a method to survey for the Scottish wildcat. Scottish Natural Heritage Commission, Inverness, Scotland, p 32. report no. 479

Kitchener AC, Yamaguchi N, Ward JM, Macdonald DW (2005) A diagnosis for the Scottish wildcat (Felis silvestris): a tool for conservation action for a criticallyendangered felid. Anim Conserv 8:223-237

Klar N, Fernández N, Kramer-Schadt S, Herrmann M, Trinzen M, Büttner I, Niemitz C (2008) Habitat selection models for European wildcat conservation. Biol Conserv 141:308-319

Korpimäki E, Krebs CJ (1996) Predation and population cycles of small mammals. Bioscience 46:754-764
Krüger M, Hertwig ST, Jetschke G, Fischer MS (2009) Evaluation of anatomical characters and the question of hybridization with domestic cats in the wildcat population of Thuringia. Germany J Zool Syst Evol Res 47:268-282

Lecis R, Pierpaoli M, Birò ZS, Szemethy L, Ragni B, Vercillo F, Randi E (2006) Bayesian analyses of admixture in wild and domestic cats (Felis silvestris) using linked microsatellite loci. Mol Ecol 15:119-131

Lin M-F, Luzon KS, Licuanan WY, Ablan-Lagman MC, Chen CA (2011) Seventy-four universal primers for characterizing the complete mitochondrial genomes of scleractinian corals (Cnidaria, Anthozoa). Zool Stud 50:513-524

Lozano J (2010) Habitat use by European wildcats (Felis silvestris) in central Spain: what is the relative importance of forest variables? Anim Biodivers Conserv 33(2):143-150

Lozano J, Malo AF (2012) Conservation of European wildcat (Felis silvestris) in Mediterranean environments: a reassessment of current threats. In: Williams GS (ed) Mediterranean ecosystems: dynamics, management and conservation. Nova Science Publishers, Hauppauge, NY, pp 1-31

Lozano J, Urra F (2007) El gato doméstico, Felis catus Linnaeus, 1758. Galemys 19:35-38

Lozano J, Virgós E, Malo AF, Huertas DL, Casanovas JG (2003) Importance of scrub-pastureland mosaics on wild-living cats occurrence in a Mediterranean area: implications for the conservation of the wildcat (Felis silvestris). Biodivers Conserv 12:921-935

Lozano J, Moleón M, Virgós E (2006) Biogeographical patterns in the diet of the wildcat, Felis silvestris Schreber, in Eurasia: factors affecting the trophic diversity. J Biogeogr 33:1076-1085

Lozano J, Virgós E, Cabezas-Díaz S, Mangas JG (2007) Increase of large game species in Mediterranean areas: is the European wildcat (Felis silvestris) facing a new threat? Biol Conserv 138:321-329

Lozano J, Casanovas JG, Virgós E, Zorrilla JM (2013) The competitor release effect applied to carnivore species: how red foxes can increase in numbers when persecuted. Anim Biodivers Conserv 36(1):37-46

Luikart G, Ryman N, Tallmon DA, Schwartz MK, Allendorf FW (2010) Estimation of census and effective population sizes: the increasing usefulness of DNAbased approaches. Conserv Genet 11:355-373

Madroño A, González C, Atienza JC (ed) (2004) Libro Rojo de las Aves de España. Dirección General para la Biodiversidad - SEO/BirdLife, Madrid

Malo AF, Lozano J, Huertas DL, Virgós E (2004) A change of diet from rodents to rabbits (Oryctolagus cuniculus). Is the wildcat (Felis silvestris) a specialist predator? J Zool 263:401-407

Martí R, Del Moral JC (ed) (2003) Atlas de las aves reproductoras de España. Dirección General de Conservación de la Naturaleza - Sociedad Española de Ornitología, Madrid

McCarthy KP, Fuller TK, Ming M, McCarthy TM, Waits L, Jumabaev K (2008) Assessing estimators of snow leopard abundance. J Wild Manage 72:1826-1833

McOrist S, Kitchener AC (1994) Current threats to the European wildcat, Felis silvestris, in Scotland. Ambio 23:243-245

Mitchell-Jones AJ, Amori G, Bogdanowicz W, Krystufek B, Reijnders PJH, Spitzenberger F, Stubbe M, Thissen JBM, Vohralík V, Zima J (1999) The atlas of European mammals. Academic Press, London

Moleón M, Sánchez-Zapata JA, Gil-Sánchez JM, Barea-Azcón JM, Ballesteros-Duper ón E, Virgós E (2011) Laying the foundations for a human-predator conflict solution: assessing the impact of Bonelli's Eagle on rabbits and partridges. PLoS One 6:e22851

Monterroso P, Brito JC, Ferreras P, Alves PC (2009) Spatial ecology of the European wildcat in a Mediterranean ecosystem: dealing with small radio-tracking datasets in species conservation. J Zool 279:27-35

Monterroso P, Castro D, Silva TL, Ferreras P, Godinho R, Alves PC (2013) Factors affecting the (in)accuracy of mammalian mesocarnivore scat identification in south-western Europe. J Zool 289:243-250

Moorhouse R, Greene T, Dilks P, Powlesland R, Moran L, Taylor G, Jones A, Knegtmans J, Wills D, Pryde M, Fraser I, August A, August C (2003) Control of introduced mammalian predators improves Kaka Nestor meridionalis breeding success: reversing the decline of a threatened New Zealand parrot. Biol Conserv 110:33-44

Muñiz MC, Sanz T (2010) Camada tardía de gato montés Felis silvestris Schreber, 1777 en el NE de la provincial de León. Galemys 22:113-114

Nowell K, Jackson P (1996) The wild cats: status survey and conservation action plan. International Union for Nature Conservation - Cat Specialist Group, Gland, Switzerland, p 382

O'Brien J, Devillard S, Say L, Vanthomme H, Léger F, Ruette S, Pontier D (2009) Preserving genetic integrity in a hybridising world: are European wildcats (Felis silvestris silvestris) in Eastern France distinct from sympatric feral domestic cats? Biodivers Conserv 18:2351-2360 
Oliveira R, Godinho R, Ettore R, Alves PC (2008) Hybridization versus conservation: are domestic cats threatening the genetic integrity of wildcats (Felis silvestris silvestris) in Iberian Peninsula? Phil Trans R Soc B 363:2953-2961

Palomo LJ, Gisbert J, Blanco JC (2007) Atlas y Libro Rojo de los Mamíferos Terrestres de España. Dirección General de Conservación de la. Naturaleza-SECEM-SECEMU, Madrid

Pierpaoli M, Birò ZS, Herrmann M, Hupe K, Fernandes M, Ragni B, Szemethy L, Randi E (2003) Genetic distinction of wildcat (Felis silvestris) populations in Europe, and hybridization with domestic cats in Hungary. Mol Ecol 12:2585-2598

Piñeiro A (2012) Eco-etología y respuestas de estrés fisiológico en el gato montés (Felis silvestris): implicaciones para su conservación. PhD dissertation. Autónoma University of Madrid

Piñeiro A, Barja I (2011) Trophic strategy of the wildcat Felis silvestris in relation to seasonal variation in the availability and vulnerability to capture of Apodemus mice. Mamm Biol 76:302-307

Piñeiro A, Barja I (2012) The plant physical features selected by wildcats as signal posts: an economic approach to fecal marking. Naturwissenschaften 99:801-809

Piñeiro A, Barja I, Silván G, Illera JC (2012) Effects of tourist pressure and reproduction on physiological stress response in wildcats: management implications for species conservation. Wild Res 39:532-539

Prugh LR, Ritland CE (2005) Molecular testing of observer identification of carnivore feces in the field. Wildl Soc Bull 33:189-194

Reynolds JC, Tapper SC (1996) Control of mammalian predators in game management and conservation. Mamm Rev 26:127-156

Rivas-Martínez S (1982) Mapa de las series de vegetación de la provincia de Madrid (1: 200,000). Diputación provincial de Madrid, Servicio forestal y medio ambiente, Madrid

Rosellini S, Barja I, Piñeiro A (2008) The response of the European pine marten (Martes martes L.) feeding to the changes of small mammal abundance. Pol Ecol 56:497-504

Sadlier LMJ, Webbon CC, Baker PJ, Harris S (2004) Methods of monitoring red foxes Vulpes vulpes and badgers Meles meles: are field signs the answer? Mamm Rev 34:75-98

Sarmento P, Cruz J, Eira C, Fonseca C (2009) Spatial colonization by feral domestic cats Felis catus of former wildcat Felis silvestris silvestris home ranges. Acta Theriol 54:31-38

Say L, Devillard S, Léger F, Pontier D, Ruette S (2012) Distribution and spatial genetic structure of European wildcat in France. Anim Conserv 15:18-27

Schaub M, Lebreton JD (2004) Testing the additive versus the compensatory hypothesis of mortality from ring recovery data using a random effects model. Anim Biodivers Conserv 27(1):73-85

Schauenberg P (1981) Elements d'ecologie du chat forestier d'Europe Felis silvestris Schreber, 1777. Rev Ecol (Terre Vie) 35:3-36

Schwartz MK, Monfort SL (2008) Genetic and endocrine tools for carnivore surveys. In: Long RA, MacKay P, Zielinski WJ, Ray JC (ed) Noninvasive survey methods for carnivores. Island Press, Washington DC, pp 238-262

Simón MA, Cadenas R, Gil-Sánchez JM, López-Parra M, García J, Fernández L, Ruiz G, López G (2009) Conservation of free-ranging Iberian lynx (Lynx pardinus) populations in Andalusia. In: Vargas A, Breitenmoser C, Breitenmoser U (ed) Iberian lynx ex situ conservation: an interdisciplinary approach. Fundación Biodiversidad, Madrid, pp 43-55

Sinclair ARE, Pech RP (1996) Density dependence, stochasticity, compensation, and predator regulation. Oikos 75:164-173

Sobrino R, Acevedo P, Escudero MA, Marco J, Gortázar C (2009) Carnivore population trends in Spanish agrosystems after the reduction in food availability due to rabbit decline by rabbit haemorrhagic disease and improved waste management. Eur J Wild Res 55:161-165

Stahl P, Artois M (1991) Status and conservation of the wild cat (Felis silvestris) in Europe and around the Mediterranean rim. Council of Europe, Strasbourg, France, p 61

Stahl P, Léger F (1992) Le chat sauvage (Felis silvestris, Schreber, 1777). Encyclopédie des Carnivores de France. Société Française pour l'Etude et la Protection des Mammifères, Bohallard and Puceul, France, p 50

StatSoft (2001) STATISTICA॰ for Windows. Vers. 6.0. StatSoft, Tulsa

Stenseth NC, Falck W, Bjornstad ON, Krebs CJ (1997) Population regulation in snowshoe hare and Canadian lynx: asymmetric food web configurations between hare and lynx. Proc Natl Acad Sci U S A 94:5147-5152

Stenseth NC, Chan KS, Tong H, Boonstra R, Boutin S, Krebs CJ, Post E, O'Donoghue M, Yoccoz NG, Forchhammer MC, Hurrell JW (1999) Common dynamic structure of Canada lynx populations within three climatic regions. Science 285:1071-1073
Sunquist M, Sunquist F (2002) Wild cats of the world. University of Chicago Press, Chicago

Thomas L, Martin K (1996) The importance of analysis method for breeding bird survey population trend estimates. Conserv Biol 10:479-490

Turchin P (2003) Complex population dynamics: a theoretical/empirical synthesis. Princeton University Press, Princeton, NJ

Tuyttens FAM, Long B, Fawcett T, Skinner A, Brown JA, Cheeseman CL, Roddam AW, Macdonald DW (2001) Estimating group size and population density of Eurasian badgers Meles meles by quantifying latrine use. J Appl Ecol 38:1114-1121

Underwood AJ (1996) Experiments in ecology. Cambridge University Press, Cambridge

Urra F (2003) El gato montés en Navarra: distribución, ecología y conservación. PhD dissertation. University Autónoma de Madrid, Madrid

Valkama J, Korpimäki E, Arroyo B, Beja P, Bretagnolle V, Bro E, Kenward R, Mañosa S, Redpath SM, Thirgood S, Viñuela J (2005) Birds of prey as limiting factors of gamebird populations in Europe: a review. Biol Rev 80:171-203

Virgós E, Travaini A (2005) Relationship between small-game hunting and carnivore diversity in central Spain. Biodivers Conserv 14:3475-3486

Virgós E, Cabezas-Díaz S, Malo AF, Lozano J, Huertas DL (2003) Factors shaping European rabbit (Oryctolagus cuniculus) abundance in continuous and fragmented populations in central Spain. Acta Theriol 48:113-122

Virgós E, Cabezas-Díaz S, Lozano J (2007) Is the endemic wild rabbit (Oryctolagus cuniculus) an endangered species in Spain? Sociological constraints in the conservation of species. Biodivers Conserv 16:3489-3504

Waits LP, Paetkau D (2005) Noninvasive genetic sampling tools for wildlife biologists: a review of applications and recommendations for accurate data collection. J Wildl Manage 69:1419-1433

Webbon CC, Baker PJ, Harris S (2004) Faecal density counts for monitoring changes in red fox numbers in rural Britain. J Appl Ecol 41:768-779

Williams D, Acevedo P, Gortázar C, Escudero MA, Labarta JL, Marco J, Villafuerte R (2007) Hunting for answers: rabbit (Oryctolagus cuniculus) population trends in northeastern Spain. Eur J Wildl Res 53:19-28

Wu J-S, Chiang P-J, Lin L-K (2012) Monogamous system in the Taiwan vole Microtus kikuchii inferred from microsatellite DNA and home ranges. Zool Stud 51:204-212

Yamaguchi N, Kitchener AC, Driscoll CA, Ward JM, Macdonald DW (2004) Craniological differentiation amongst wild-living cats in Britain and southern Africa: natural variation or the effects of hybridisation? Anim Conserv 7:339-351

Zar JH (1984) Biostatistical analysis. Prentice-Hall, Englewood Cliffs, NJ

Zuberogoitia I, Campos MA, Torres JJ, Onrubia A, Campos LF, de Buruaga MS (2001) El gato montés en el Parque Natural de Urkiola. Podemos considerar extinguida la especie? Est Mus Cienc Nat Álava 16:200-205

Zuercher GL, Gipson PS, Stewart GC (2003) Identification of carnivore feces by local peoples and molecular analyses. Wildl Soc Bull 31:961-970

\section{doi:10.1186/1810-522X-52-16}

Cite this article as: Lozano et al:: Monitoring European wildcat Felis silvestris populations using scat surveys in central Spain: are population trends related to wild rabbit dynamics or to landscape features? Zoological Studies 2013 52:16.

\section{Submit your manuscript to a SpringerOpen ${ }^{\odot}$ journal and benefit from:}

- Convenient online submission

- Rigorous peer review

- Immediate publication on acceptance

- Open access: articles freely available online

- High visibility within the field

- Retaining the copyright to your article

Submit your next manuscript at $\gg$ springeropen.com 